\title{
Global epidemiology of coronavirus disease 2019 and lessons for effective control of this and future pandemics
}

\author{
Emmanuel Okechukwu Njoga1(D), Yusuf Feyisara Zakariya²(D), Ishmael Festus Jaja ${ }^{3}$ (D), Chinwe Elizabeth Okoli ${ }^{4}$ and \\ Philip Paul Mshelbwala5 ${ }^{5}$
}

\begin{abstract}
1. Department of Veterinary Public Health and Preventive Medicine, Faculty of Veterinary Medicine, University of Nigeria, Nsukka 410001, Nigeria; 2. Department of Mathematical Sciences, Faculty of Engineering and Science, University of Agder, Kristiansand, Norway; 3. Department of Livestock and Pasture Science, University of Fort Hare, Alice 5700, South Africa; 4. Department of Veterinary Public Health and Preventive Medicine, Faculty of Veterinary Medicine, University of Abuja, Federal Capital Territory, Abuja, Nigeria; 5. Spatial Epidemiology Laboratory, School of Veterinary Science, University of Queensland, Brisbane, Queensland, Australia.
\end{abstract}

Corresponding author: Yusuf Feyisara Zakariya, e-mail: yusuf.zakariya@uia.no

Co-authors: EON: njoga.emmanuel@unn.edu.ng, IFJ: ijaja@ufh.ac.za, CEO: chinwe4greatness@gmail.com, PPM: p.mshelbwala@uq.edu.au

Received: 18-11-2020, Accepted: 05-02-2021, Published online: 16-03-2021

doi: www.doi.org/10.14202/IJOH.2021.78-87 How to cite this article: Njoga EO, Zakariya YF, Jaja IF, Okoli CE, Mshelbwala PP (2021) Global epidemiology of coronavirus disease 2019 and lessons for effective control of this and future pandemics, Int. J. One Health, 7(1): 78-87.

\begin{abstract}
Barely 1 year after severe acute respiratory syndrome coronavirus-2 (SARS-CoV-2) was first reported in China, the virus has infected approximately 120 million people, caused around 3 million deaths, and adversely affected the global economy. Despite stringent measures to flatten the epidemiologic curve of the pandemic, there have been spikes and waves of the infection in many countries, particularly in the American, European, and Asian continents. This review critically evaluated the global epidemiology of the novel coronavirus disease 2019 (COVID-19) to provide advice on other possible ways of managing the disease as various COVID-19 vaccines are being rolled out. To effectively control this and possible future epidemics/pandemics, there is a need to maintain a healthy balance between saving lives and livelihoods in the implementation of lockdowns. Unwarranted human exposures to animals, particularly pangolins, civet cats, bats, dromedary camels, and other wildlife known to be reservoirs and intermediate hosts of coronaviruses should be prevented. All the identified strains of SARS-CoV-2, including the highly infectious UK and South African variants, should be incorporated in COVID-19 vaccine production; to widen the protection spectrum. Some of the COVID-19 vaccines require primary inoculation, booster vaccination after 2-4 weeks and annual revaccination for adequate immunization against SARS-CoV-2. Survivors of COVID-19 may require only a single vaccine dozing and annual revaccination thereafter. Adoption of One Health approach and the development of globally coordinated active surveillance systems against emerging and reemerging zoonotic viruses are imperative.
\end{abstract}

Keywords: COVID-19, coronaviruses, emerging zoonoses, new variant SARS-CoV-2, pandemic diseases, SARS-CoV-2, public health.

\section{Introduction}

The 2019 novel coronavirus (2019-nCoV) is the etiologic agent responsible for clusters of a strange form of acute respiratory distress syndrome that emanated from China in 2019. The disease was later named coronavirus disease 2019 (COVID-19) by the World Health Organization (WHO) on February 11, 2020 [1]. The virus was first isolated from the bronchoalveolar lavage fluid of suspected COVID-19 patients on December 30, 2019, in China [1,2]. After sequencing and conducting an evolutionary tree analysis of the 2019-nCoV, severe acute respiratory syndrome coronavirus-2 (SARS-CoV-2) was the nomenclature given to the virus by the WHO and the International Committee on Taxonomy of Viruses [1].

Copyright: Njoga, et al. This article is an open access article distributed under the terms of the Creative Commons Attribution 4.0 International License (http://creativecommons.org/licenses/ by/4.0/), which permits unrestricted use, distribution, and reproduction in any medium, provided you give appropriate credit to the original author(s) and the source, provide a link to the Creative Commons license, and indicate if changes were made. The Creative Commons Public Domain Dedication waiver (http:// creativecommons.org/ publicdomain/zero/1.0/) applies to the data made available in this article, unless otherwise stated.
SARS-CoV-2 is an enveloped virus with a positive-sense single-stranded RNA genome and a nucleocapsid of helical symmetry [3]. SARS-CoV-2 belongs to the genus Betacoronavirus, subfamily Orthocoronavirinae, family Coronaviridae, and order Nidovirales [4,5]. SARS-CoV and the Middle East respiratory syndrome coronavirus (MERS-CoV) are also members of the genus Betacoronavirus, which is further classified into five subgenera: Embecovirus, Hibecovirus, Merbecovirus, Nobecovirus, and Sarbecovirus [4-6]. The three human coronaviruses (SARS-CoV, MERS-CoV, and SARS-CoV-2) belong to the subgenera Sarbecovirus [5]. Genome phylogenic analysis indicates that SARS-CoV and MERS-CoV have $79 \%$ and $50 \%$ genomic resemblance with SARSCoV-2, respectively [7]. Similarly, the COVID-19 virus has approximately $92 \%$ genetic resemblance to the pangolin coronavirus [8], and this has lent credence to the suspicion that SARS-CoV-2 is of animal origin. In addition, bats, civet cats and pangolins may play crucial roles in the epidemiology of SARS-CoV-2 as the reservoirs or intermediate hosts $[9,10]$, as shown in Figure-1. 


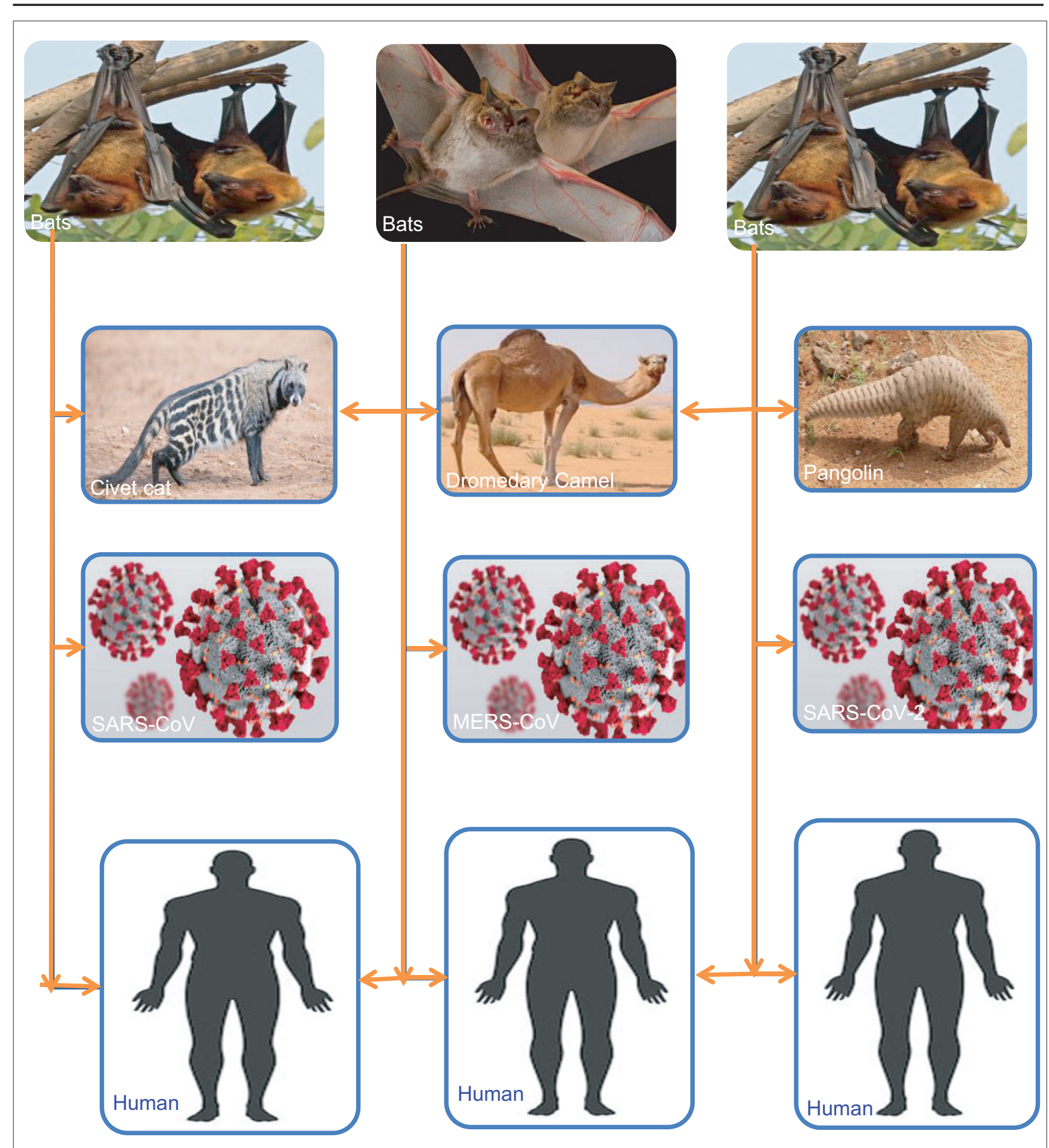

Figure-1: Schematic representation of the roles of bats, civet cats, pangolins and dromedary camels in the epidemiology of zoonotic betacoronaviruses, as the major reservoirs and transmitters of the pathogens to humans. Severe acute respiratory syndrome coronavirus, Middle East respiratory syndrome coronavirus, and SARS-CoV-2 are transmissible to humans from civet cats, dromedary camels, and pangolins, respectively. Human-to-human and human-to-animal transmissions of these viruses are very common.

SARS-CoV-2 is thought to have emerged from an international seafood market in Wuhan city, Hubei Province, China, in December 2019 [11]. The China global seafood/wildlife market is famous for its extensive trade in different species of animals such as bats, pangolins, minks, snakes, reptiles, rodents, porcupines, and Chinese bamboo rats. Just like other zoonotic coronaviruses, there is evidence that SARS$\mathrm{CoV}-2$ emerged from bats and reached humans, likely after jumping to pangolin or civet cat intermediate hosts $[12,13]$. Illegal animal trade and wildlife smuggling are multibillion-dollar businesses worldwide which may enhance the chances of viral assortment of coronaviruses from different species; for onward transmission to humans, particularly at the wildlife-human interface [14].

The COVID-19 virus is both infectious and contagious. The virus is essentially transmitted between 
people through respiratory droplets and infectious fomites. The disease is characterized by a life-threatening and highly contagious pneumonia with the possibility of failure of one or more organs occurring as a complication. The most common symptoms of the disease are fever, dry cough, respiratory difficulty, shortness of breath, sore throat, chest pain, frequent sneezing, and general body malaise. Recent findings in 2020 show that the COVID-19 virus can retain viability on plastics and stainless steels for approximately 3 days but does not survive for more than a day on cardboard or more than $4 \mathrm{~h}$ on copper [15]. Similar to other enveloped viruses, soaps and other detergents destroy the lipid bilayer of the SARS-CoV-2 envelope and inactivate the pathogen.

As an emerging zoonosis, the best treatment option for the management of COVID-19 is still being determined because there is presently no globally approved drug for the treatment. However, claims and counterclaims over the efficacy of some anti-malaria and antiviral drugs in the management of the disease have emerged. Although chloroquine and hydroxychloroquine were initially described as "promising drugs" for the treatment of COVID-19 [16], this was later withdrawn due to toxicity concerns, particularly at high doses in patients with underlying health conditions [17]. In some clinical trials, remdesivir - an antiviral drug used against Ebola and other viruses - has been described as a "promising therapeutic candidate" for the management of COVID-19 [18]. The drug was said to be relatively safe [19] and shortens recovery time in hospitalized patients $[18,19]$. However, unlike in Ebola, the efficacy of remdesivir for COVID19 treatment is doubtful as it did not meet efficacy endpoints in a randomized trial [18]. In addition, the drug may not be available or affordable in most developing counties. Therefore, the emphasis is on the prevention and containment of the disease.

In a bid to limit the morbidity and mortality of COVID-19, governments at various levels have implemented several restrictions on human movement and interactions, which have taken their toll on the global economy and quality of life. Despite these measures, the disease is far from being controlled in most parts of the world. At present, some countries are even experiencing spikes and waves of the infection. During the winter/harmattan season, the disease and its untoward consequences may even worsen, as obtains in most respiratory diseases. The continued spikes and waves of COVID-19 in most countries necessitated the need to study and analyze the distribution, patterns, and determinants of SARS-COV-2 infection worldwide in order to restrategize for effective control of the pandemic. Therefore, this paper reviewed the global epidemiology of SARS-CoV-2 cases and fatalities and made suggestions on new measures to tame the tide of the rising infection at the global stage and to prevent future pandemics or epidemics.

\section{Epidemiology of SARS-CoV-2 Infections}

\section{Morbidity of SARS-CoV-2}

As of March 1, 2021, SARS-CoV-2 infections have been reported in 218 countries/territories across all continents [20]. The virus has infected approximately 120 million people, of whom more than 2.6 million have died of the disease [20]. Most of the active cases have been mild, while less than $2 \%$ were severe or in critical condition [20]. The top five most infected countries (which accounted for $51 \%$ of the global COVID-19 cases) in decreasing order were the US, India, Brazil, Russia, and UK.

The WHO data on the regional distribution of SARS-CoV-2 cases as of March 1, 2021, show that the Americas, Europe, and Southeast Asia were responsible for approximately 51 million, 39 million, and 14 million cases, respectively [20]; which amounted to approximately $87 \%$ of the global COVID-19 cases (Figure-2). The West Pacific and Africa regions reported fewer SARS-CoV-2 cases (only $4.3 \%$ of the global cases). Consequently, the regional distributions of SARS-CoV-2 cases in decreasing order were as follows: The Americas, Europe, Southeast Asia, Eastern Mediterranean, Africa, and the West Pacific. The top five countries that reported the highest number of cases in each of the regions are shown in Table-1. In the African region, the South and North sub-regions were the epicenters of SARS-CoV-2 infection as these areas accounted for most of the reported COVID-19 cases in Africa [20]. Older adults and the elderly were the most affected, as evidenced in the WHO report [20] on the age distribution of the infection presented in Figure-3.

\section{Infectivity of SARS-CoV-2}

The spread of SARS-CoV-2 to over 120 million people in approximately 218 countries/territories in just about 12 months of its emergence [20] attests to the high infectivity of the virus and ease of transmission. Scientists believe that the new mutant SARSCoV-2 variants, particularly the UK (B.1.1.7) and the South African (B.1.351) strains, are highly infectious



Figure-2: Percentage distribution of the globally confirmed cases of severe acute respiratory syndrome coronavirus-2 across the four most affected WHO regions as at March 1, 2021 (Source: https://covid19.who.int/). 
Table-1: Cases, fatalities, and case-fatality rates of SARS-COV-2 in top five most affected countries across each of the six WHO regions.

\begin{tabular}{|c|c|c|c|c|c|}
\hline WHO regions & Countries & $\begin{array}{l}\text { Dates of index } \\
\text { case }\end{array}$ & $\begin{array}{l}\text { Confirmed } \\
\text { cases }\end{array}$ & $\begin{array}{c}\text { Confirmed } \\
\text { fatalities }\end{array}$ & $\begin{array}{c}\text { Case fatality } \\
\text { rates }(\%)\end{array}$ \\
\hline \multirow[t]{5}{*}{ Africa } & South Africa & March 5, 2020 & 714,246 & 18,944 & 2.65 \\
\hline & Ethiopia & March 13, 2020 & 92,856 & 1419 & 1.53 \\
\hline & Nigeria & February 27, 2020 & 61,930 & 1129 & 1.82 \\
\hline & Algeria & February 25, 2020 & 55,620 & 1897 & 3.41 \\
\hline & Kenya & March 12, 2020 & 48,490 & 896 & 1.85 \\
\hline \multirow{5}{*}{ Americas } & USA & January 20, 2020 & $8,485,747$ & 223,328 & 2.63 \\
\hline & Brazil & February 26, 2020 & $5,380,635$ & 156,903 & 2.92 \\
\hline & Argentina & March 3, 2020 & $1,081,336$ & 28,612 & 2.65 \\
\hline & Colombia & March 6, 2020 & $1,007,711$ & 30,000 & 2.98 \\
\hline & Mexico & February 28, 2020 & 886,800 & 88,743 & 10.01 \\
\hline \multirow[t]{5}{*}{ Eastern Mediterranean } & Iran & February 19, 2020 & 568,896 & 32,616 & 5.73 \\
\hline & Iraq & February 22, 2020 & 451,707 & 10,633 & 2.35 \\
\hline & Saudi Arabia & March 2, 2020 & 344,879 & 5296 & 1.54 \\
\hline & Pakistan & February 26, 2020 & 327,895 & 6736 & 2.05 \\
\hline & Morocco & March 2, 2020 & 197,489 & 3301 & 1.67 \\
\hline \multirow[t]{5}{*}{ Europe } & Russia & January 31, 2020 & $1,513,877$ & 26,050 & 1.72 \\
\hline & France & January 24, 2020 & $1,055,942$ & 34,362 & 3.25 \\
\hline & Spain & January 31, 2020 & $1,046,132$ & 34,752 & 3.32 \\
\hline & UK & January 31, 2020 & 854,014 & 44,745 & 5.24 \\
\hline & Italy & January 31, 2020 & 504,509 & 37,210 & 7.38 \\
\hline \multirow{5}{*}{ Southeast Asia } & India & January 30, 2020 & $7,090,959$ & 119,014 & 1.68 \\
\hline & Bangladesh & March 8, 2020 & 398,515 & 5803 & 1.46 \\
\hline & Indonesia & March 2, 2020 & 389,712 & 13,299 & 3.41 \\
\hline & Nepal & January 9, 2020 & 158,089 & 847 & 0.54 \\
\hline & Myanmar & March 23, 2020 & 44,774 & 1095 & 2.25 \\
\hline \multirow[t]{5}{*}{ West Pacific } & Philippines & January 30, 2020 & 370,028 & 6977 & 1.89 \\
\hline & Japan & January 16, 2020 & 97,074 & 1718 & 1.77 \\
\hline & China & December 1, 2019 & 91,701 & 4746 & 5.18 \\
\hline & Singapore & January 23, 2020 & 57,970 & 28 & 0.05 \\
\hline & Australia & January 25, 2020 & 27,520 & 905 & 3.29 \\
\hline
\end{tabular}

The values presented are as reported on WHO COVID-19 dashboard as at October 26, 2020. SARS-COV-2=Severe acute respiratory syndrome coronavirus- 2

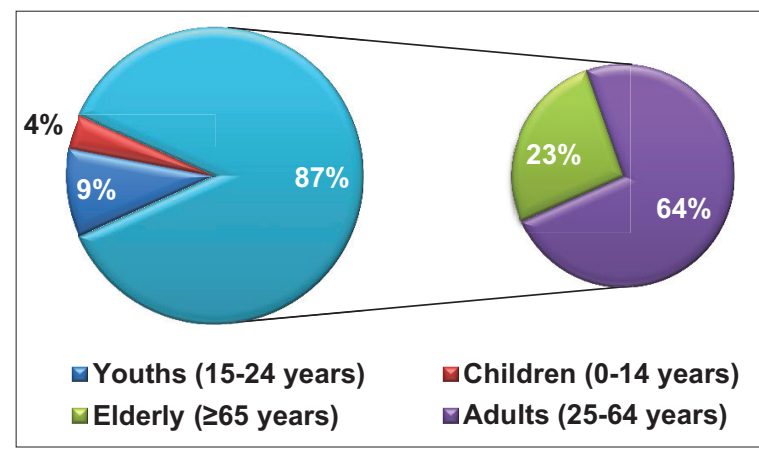

Figure-3: Percentage distribution of globally confirmed severe acute respiratory syndrome coronavirus-2 cases across different age groups. Adults and the elderly accounted for $87 \%$ of the cases. (Source: https://covid 19 . who.int/).

and contagious and are therefore driving the current surge in COVID-19 cases worldwide. Rapid human cross-border movement and viability of the virus under certain conditions that are lethal to some other viruses may also be enhancing the disease spread. In the dry and wet forms, SARS-CoV-2 was reported to have retained viability for up to 3 and 7 days respectively, at ambient temperature $\left(20-25^{\circ} \mathrm{C}\right)$ [21]. The virus also retained viability within a $\mathrm{pH}$ range of 4-11 for several days and for 1-2 days in stool samples preserved at room temperature $\left(20-25^{\circ} \mathrm{C}\right)[21]$. However, some commonly used disinfectants and laboratory inactivation procedures effectively inactivated or reduced viability of the virus [21]. In addition, SARS-CoV-2 does not survive for more than a day on cardboard or more than $4 \mathrm{~h}$ on copper $[15,21]$. These findings could be exploited for effective control of the spread of COVID-19 in the affected countries/territories.

\section{Mortality of SARS-CoV-2}

As of March 1, 2021, there were approximately 3 million deaths associated with SARS-CoV-2 infection in 218 countries/territories [20]. More than 75\% of the global SARS-CoV-2 deaths occurred in 12 countries, most of which are developed or industrialized countries [20]. The top five countries that reported the highest number of COVID-19 deaths in descending order were the US, Brazil, Mexico, India and the UK [20]. The distributions of confirmed COVID-19 fatalities among countries that have reported at least 1000 cases are shown in Figure-4. The global case-fatality rate of SARS-CoV-2 ranges between $2 \%$ and $3 \%$, but those of Mexico, Italy, Iran, and the UK were much higher at $10 \%, 7.38 \%, 5.73 \%$, and $5.24 \%$, respectively [20].

On the continental level, data on COVID-19 deaths at the European Center for Disease Prevention 


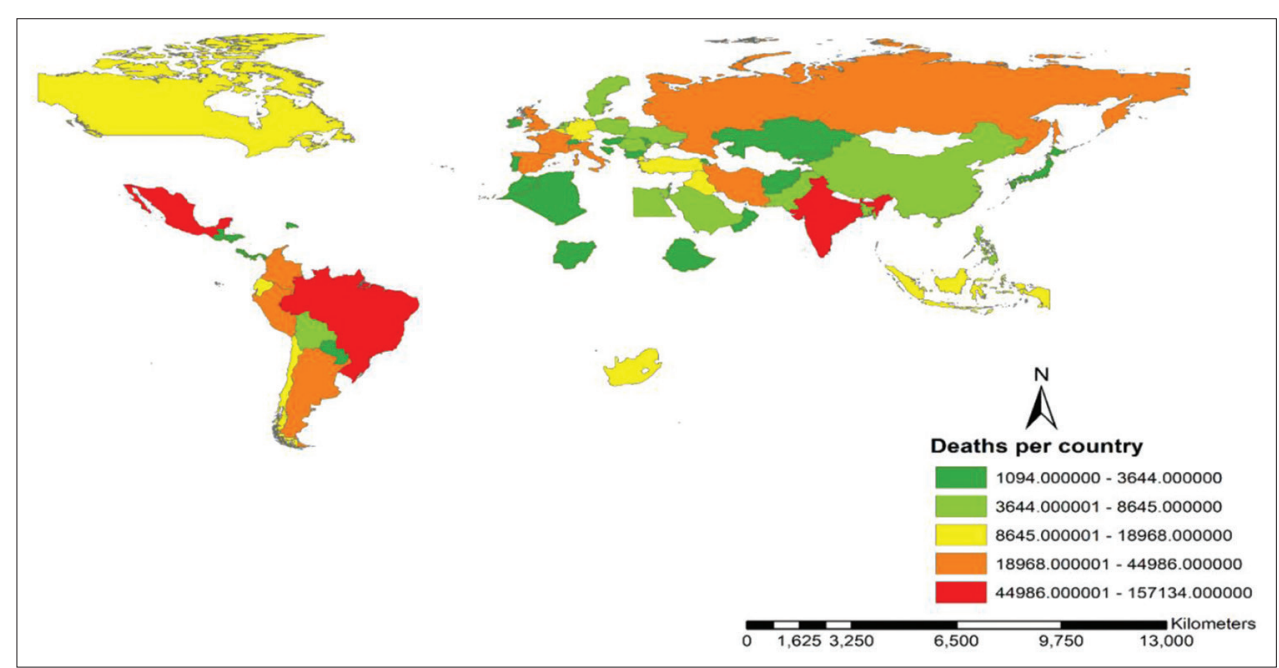

Figure-4: Top countries of the world with confirmed coronavirus disease 2019 fatality of at least 1000 cases as at November 30, 2020 (Source: https://covid19.who.int/).

and Control as of March 1, 2021 [22], showed that the American, European, and Asian continents (in decreasing order) reported the highest number of COVID-19 fatalities (Figure-5) and accounted for approximately $94 \%$ of the globally reported deaths. The American and African continents reported approximately $46 \%$ and $4 \%$ of the globally reported COVID-19 fatalities, respectively. The top five countries that reported the highest numbers of COVID-19 deaths across each of the six WHO regionsare shown in Table-1.

\section{Gender and age differences in global COVID-19 cases and fatalities}

Comprehensive reports on the demographics of COVID-19 fatalities at the global or continental levels are difficult to obtain because most countries do not indicate gender or age in the reported cases or deaths [20]. For example, data from the Centers for Disease Control (CDC) showed that as of November 9,2020 , only $70 \%$ and $76 \%$ of the reported COVID19 fatalities in the America contained information on the gender and age of the deceased persons, respectively [23]. Demographic data from the CDC indicated that $53 \%$ and $47 \%$ of COVID-19 deaths in the US were males and females, respectively [23]. Similarly, a recent study (October 2020) in Mexican hospitals showed that $75 \%$ of COVID-19 fatalities were men with an average age of 62.9 years [24].

The fact that men tend to smoke more and are more likely to disregard public health advice on SARS$\mathrm{CoV}-2$ prevention protocols may be partly responsible for the apparent gender-based bias in global SARSCoV-2 susceptibility and mortality [25]. In addition, women have more robust immune systems than men because they possess a pair of X-chromosomes, which unlike the Y-chromosome in men contains most of the immune-associated genes [26,27]. The expression of angiotensin-converting enzyme-2, which is the main receptor for SARS-CoV-2, is higher in males than in females $[26,27]$. Furthermore, female hormones may play a role in susceptibility to Coronavirus infections.



Figure-5: Pictorial representation of COVID-19 casefatality ratio, as at March 1, 2021, among top four most affected continents (Source: https://www.ecdc.europa.eu/ en/geographical-distribution-2019-ncov-cases).

In 2017, scientific evidence showed that female mice were less susceptible to SARS-CoV infection than males [28]. However, the gender-based differences in susceptibility to the virus disappeared following ovariectomy, suggesting that the production of estrogen may have been responsible for the sex-based vulnerability differences [28].

Furthermore, it appears that SARS-CoV-2 not only discriminates by sex but also by age and the presence of underlying health conditions. Published reports indicate that older adults and the elderly are at an increased risk of death following SARS-CoV-2 infection $[29,30]$. The age distributions of COVID-19 mortalities in some countries showed only small variations, although the number of deaths per country showed considerable variation [29]. These findings imply that age alone may not be a significant determinant of death following SARS-CoV-2 infection; rather, the immune status of the patient and/or presence of underlying medical condition(s) may play prominent roles.

To effectively suppress and/or eliminate SARS$\mathrm{CoV}-2$, the host's immune system must recognize 
the virus as an antigen and initiate sufficient humoral and/or cellular-mediated immune response to destroy and clear off the virus from the body. However, these immune mechanisms are usually inadequate in some older adults or the elderly [29]. The major preexisting comorbidities that negatively influence survival outcomes in COVID-19 geriatric patients are leukocytopenia (particularly lymphopenia and neutropenia), hypertension, cardiovascular diseases, type 2 diabetes mellitus, kidney diseases, and chronic obstructive pulmonary diseases [30]. The age susceptibility to COVID19 may be due to a significant reduction in innate and adaptive immune responses in the elderly [31]. At the later stage of life, there is a marked decrease in the expression and function of innate immune receptors and signal systems, leading to defective activation and decreased functionality of the immune cells [24,28-31].

Similarly, as one age, there is a depopulation of naive T-lymphocytes in the body as the immature cells differentiate into memory T-cells [31]. Unfortunately, the replenishment of naive T-lymphocytes decreases with age, giving rise to an imbalance in the number of immune cells and hence the reduced immune response to SARS-CoV-2 infection [24,31]. To give credence to the above, the lymphocyte-to-neutrophil ratio (LNR) and the neutrophil-to-monocyte ratio (NMR) in severely ill COVID-19 patients were found to be predictors of in-hospital deaths in Mexico [24]. Specifically, there were 4-fold decreases in the LNR and 2-fold increases in the NMR in patients who died of COVID-19 in Mexico [24].

\section{Transmission of SARS-CoV-2}

SARS-CoV-2 essentially spreads through inhalation [32] and possibly through the fecal-oral route. The presence of SARS-CoV-2 RNA has been demonstrated in stool [33], which might suggest the possibility of transmission through the fecal-oral route, but such transmission has not been reported. The inhalation of infectious droplets and aerosols produced during coughing or sneezing by infected individuals is the major means of interpersonal transmission of the virus [34]. Respiratory droplets refer to relatively heavy infectious agents that are greater or equal to $5-10 \mu \mathrm{m}$ in diameter [20]. Proximity of $>2 \mathrm{~m}$ from the infected person seems to be an essential prerequisite for transmission through the inhalation of infectious droplets because the droplets; are relatively heavy and do not usually travel more than $2 \mathrm{~m}$ before settling on surfaces [32]. The virus also spreads through contact with contaminated surfaces (fomites) in the immediate surroundings of infected persons [34]. SARS-CoV-2 RNA has been detected in semen [35] and breast milk [36] of infected persons, but there has not been any evidence of the transmission through coitus or breastfeeding. Evidences of SARS-CoV-2 infections in pets, various farm animals, and wildlife have also been reported [37,38], and proofs of zoonotic transmission of the virus have been documented $[39,40]$.

\section{COVID-19 in developing and malaria-endemic countries}

Contrary to the pessimistic predictions on the possible devastating morbidity and mortality of SARS-CoV-2 in developing countries, which are backward in terms of health-care facilities and services, it is somewhat surprising that these countries have recorded minimal numbers of COVID-19 cases and deaths. For example, as of March 1, 2021, data posted on the COVID-19 dashboard of the European Center for Disease Prevention and Control [22] indicated that Africa contributed only approximately $3.3 \%$ and $4 \%$ of the 120 million cases and 2.6 million COVID-19 deaths, respectively [22]. The reasons behind the low COVID-19 cases and mortalities in developing countries have been mostly speculative or elusive, but a few factors may be responsible.

Prominent among these factors may be low testing for COVID-19 and the lack of medical reports on the causes of deaths due to home management of suspected COVID-19 cases. For example, in Nigeria, which is the seventh most populated country worldwide with an estimated population of 207 million [41], data provided by the Nigeria Centre for Disease Control showered that only 1,489,103 COVID-19 tests had been conducted as of February 27, 2021 [42]. Of those tested, 155,076 were positive, corresponding to a test-positivity ratio of $9.6(10.4 \%$ of those tested were positive). The total number tested represented only $0.72 \%$ of the population. It is most likely that if more tests were conducted, the number of reported cases would have been much higher. The same scenario may be playing out in other developing countries and thus may be responsible for the low number of COVID-19 cases and deaths being reported. Furthermore, scientific evidences suggest that the elderly and those with underlying health conditions are most disproportionately affected $[29,30]$. In Africa, these groups of people often reside in dispersed rural settings [43] where COVID-19 testing may be unlikely.

There seems to be a negative correlation between SARS-CoV-2 infections/deaths and malaria endemicity/exposure. The number of COVID-19 cases per million was negatively correlated with malaria endemicity in 108 countries across the globe [44]. Malariafree countries not only recorded higher numbers of COVID-19 infections but also reported more fatalities compared with high malaria-endemic countries [44]. These findings suggest that natural immune responses against malaria may provide heterologous protection against SARS-CoV-2, and this may explain the low morbidity and mortality rates of COVID-19 in developing and malaria-endemic countries. The correlation may also explain the prima facie justification for the use of antimalarial drugs (chloroquine and hydroxychloroquine) in the management of COVID-19 [16,17].

Certain antimalarial drugs have been shown to possess some antiviral activities that inhibit the 
receptors responsible for the adhesion and binding of SARS-CoV-2 to human cell [45]. The drugs also limit the replication of the virus by blocking the lysosomal and enzymatic activities required for the process. These antiviral activities may help to curtail the overactivation of the immune system in COVID-19 patients, thereby slowing the progression and severity of the disease [45].

Finally, the youthful population of most developing countries, particularly in Africa, may explain the low COVID-19 morbidity and mortality rates reported. Nineteen of the world's 20 youngest countries are in Africa [43]. Since youthful populations appear to be less susceptible to SARS-CoV-2 infection and may also fight off the condition better than the elderly population [29], the low morbidity and mortality rates of COVID-19 in Africa are, therefore, not entirely surprising.

\section{Lessons for effective control of COVID-19 and other possible future pandemics}

Epidemiologically speaking, "control" is the first and most crucial step toward the elimination/ eradication of diseases that have attained an epidemic or pandemic status. This necessitated the lockdowns, border closures, travel bans, and other forms of social restrictions imposed by various governments across the globe. However, these measures have not fully achieved the desired result because COVID-19 is neither controlled nor eradicated at the global stage. Instead, there have been spikes and waves of the infection in most countries to the extent that some of these nations are currently enforcing third lockdowns despite the associated severe economic and social consequences.

Cognizant of the foregoing situation, there are several pertinent questions to ask. What is wrong with the current containment measures being deployed? Why has the epidemiologic curve of COVID-19 refused to flatten in most countries? Why are we experiencing spikes and waves of COVID-19 when the incidence should be decreasing? Are lockdown and other forms of social restrictions the only way out of this pandemic? Should we consider a different approach for the disease control as COVID-19 vaccines are being rolled out? There are no easy answers to these questions, but drawing inferences from past and present epidemics/pandemics may provide some lessons for the effective control of this and future pandemics, as suggested below.

1. Rather than total lockdown and border closure, aggressive testing, contact tracing, case isolation, and quarantine of exposed individuals may suffice. For example, in China, where the pandemic first emerged, lockdowns and travel restrictions only delayed the overall epidemic progression by just 3-5 days [46]. However, these restrictions decreased international case importation of COVID-19 by approximately $80 \%$ [46]. This implies that while border closure effectively prevented case importation or exportation of the virus, lockdowns within the country only delayed but did not prevent the disease spread. It also implies that lockdowns, despite the economic and social implications, cannot completely prevent interpersonal interactions and hence the disease spread. It is possible that preventing case importation through timely border closure and intracity spread of the disease through aggressive testing, contact tracing, isolation of confirmed cases, and quarantine of suspected or exposed individuals could have sufficed. However, border closure as a means of containment of a pandemic must be implemented before the disease is imported or the purpose of the closure will be ultimately defeated.

2. Enacting impromptu social restriction rules alone may not be enough to contain an infectious or contagious disease that has attained a pandemic status. This likely explains why social restriction measures deployed against COVID-19 have not eliminated the disease spread in most affected countries. Instead, there have been waves of the disease despite restrictions. There is a need to continuously and systematically educate or engage the masses on the need to obey these rules for public health safety. For example, most persons in Nigeria still believe that COVID-19 is a hoax, and they only use face masks in public to evade police harassments [47]. In addition, in South Africa, people jettison social distancing rules during funerals and religious gatherings, and this is thought to have been the primary cause of COVID-19 spikes, ravaging the country more than any other in Africa [48]. These findings underscore the need for increased public enlightenment of the importance of obeying the recommended public health protocols for COVID-19 prevention.

Various governments have already done a lot in this regard. However, in some countries, people do not always trust their government and hence may dismiss any information from the political leaders as mere politicians' statements. Where the above is the case, the government should engage respected religious, traditional, or community leaders for adequate public enlightenment since these individuals may command much public trust. Since the government alone cannot cater for all the needs in society, cooperative bodies, charities, and non-governmental organizations can lead a sustained grass-roots public enlightenment campaign against COVID-19.

3. There is a need for political leaders to obey the recommended public health directives to control COVID-19 and put systems in place to make it easier for citizens to comply with the rules. For example, the rule on compulsory use of face masks in public places could be accompanied by the free distribution of the same to people who 
cannot afford them. Facilities for hand sanitizing and/or disinfection could be mounted at strategic public places such as markets, schools, and places of worship. Palliatives and all forms of social benefits should be provided, particularly to the unemployed, to enable them to cope with stay-athome orders. As this is on-going, contact tracing systems, isolation of all cases, and quarantining of contacts should be intensified. These actions can flatten the epidemiologic curve faster and hence prevent subsequent mandatory stay-at-home order for everyone.

4. The disparities in gender and age vulnerability to COVID-19 infections and fatalities emphasize the need to tailor the disease treatment, when found, according to sex and age. Since the Rhesuspositive $(\mathrm{O}+)$ blood group was the least affected by SARS-CoV-2 in Sudan [49], the search for COVID-19 treatment could also evaluate the ABO blood grouping system to unravel the mystery behind the disease survivability based on blood groups.

5. It is pertinent to limit unnecessary human incursions into wildlife habitats and other forms of exposure to animal reservoirs of zoonotic pathogens. In the last few years, the world has experienced various epidemics, including avian flu, SARS-CoV, swine flu, MERS-CoV, Ebola, and now SARS-CoV-2. All these epidemics/pandemic/public health emergencies have been linked to animals, particularly wildlife [50]. It may be time to rethink all forms of needless human-animal interactions, including having wild animals as pets, hunting bats for meat during bat festivals, and illegal wild animal trade, particularly at the international level [14,51]. These practices facilitate inter- and intra-species spread of zoonotic viruses and make it easy for these pathogenic viruses to jump species levels. Therefore, curtailing unwarranted exposure to wildlife through advocacy and international legislation that could be implemented using a coordinated One Health approach may be worthwhile.

6. There is a need for epidemic preparedness and strengthening of the health system, particularly in developing countries. This could be achieved through increased budgetary allocations to the health sector and enhanced surveillance for emerging and reemerging infections. Since health workers are critical for a rapid response to any epidemic or pandemic, they should be well remunerated, and adequate personal protective equipment provided at all times. Additionally, international partnerships for active surveillance against emerging zoonoses and prompt reporting of strange diseases are paramount for timely detection of early disease warnings and to avert future epidemics or pandemics.

7. The six major identified strains (L, S, V, G, GR, and GH strains) of SARS-CoV-2 [52], as well as the highly infectious new variant strains first detected in the UK, South Africa and recently in Brazil [53], should be incorporated in the various COVID-19 vaccines being produced. The UK and South African mutants strains are about $70 \%$ more infectious, have been detected in over 100 countries and territories [20] and are also the predominant strains spreading in European and the American continents [54]. Therefore, incorporation of these and indeed all identified strains of SARS-CoV-2 in the various COVID-19 vaccines being produced will greatly enhance their protection spectrum. This is paramount because the vulnerability of COVID-19 survivors to subsequent SARS-CoV-2 infections suggests that the antibodies to various strains of the virus may not be cross-protective or that the natural immunity may be transient.

8. Since ambient temperature and humidity seem to adversely affect the viability and spread of SARSCoV-2 [55], this useful epidemiological finding could help countries and health institutions make better plans for the provision of effective health services during the winter, when the disease is expected to surge due to cold weather conditions.

\section{Conclusion}

As the effort to effectively control the pandemic intensifies, there is a need to maintain a healthy balance between saving lives and livelihoods in implementing disease containment measures. Rather than a total lockdown, early border closure on notification of an exotic disease or epidemic outbreak may suffice for the prevention of international case importation. There is a need for epidemic preparedness and strengthening of the health system, particularly in developing countries. Illegal trade in wild animals and all unwarranted human-animal interactions, particularly at the human-wildlife interface, should be curtailed. All the identified SARS-CoV-2 strains, including the highly infectious new variant strains found in the UK, South Africa, Europe, Brazil, and the US, should be incorporated in COVID-19 vaccines to widen the protection spectrum. More public enlightenment and advocacy are required for the acceptance of COVID-19 vaccines and strict compliance with the disease prevention protocols. Primary inoculation with COVID-19 vaccine, booster vaccination after 2-4 weeks and annual revaccination is required for adequate immunization against SARSCoV-2. Survivors of COVID-19 may only require single dozing and annual revaccination thereafter. Adoption of One Health approach and development of globally coordinated active surveillance systems against emerging and reemerging zoonotic viruses is imperative to nip future epidemics/pandemics at the bud.

\section{Authors' Contributions}

EON and IFJ conceived the work. EON did the literature search, collated the data and drafted the 
original manuscript. YFZ, CEO, IFJ and PPM edited the draft. All authors read and approved the final manuscript.

\section{Acknowledgments}

The authors are grateful to the University of Agder, Kristiansand, Norway for paying the article processing fees of this paper.

\section{Competing Interests} interests.

The authors declare that they have no competing

\section{Publisher's Note}

Veterinary World (Publisher of International Journal of One Health) remains neutral with regard to jurisdictional claims in published map and institutional affiliation.

\section{References}

1. World Health Organization. Naming the Coronavirus Disease (COVID-19) and the Virus that Causes it. World Health Organization, Geneva. Available from: https://www. who.int/emergencies/diseases/novel-coronavirus-2019/ technical-guidance/naming-the-coronavirus-disease(covid-2019)-and-the-virus-that-causes-it. Retrieved on 09-11-2020.

2. Zhu, N., Zhang, D., Wang, W., Li, X., Yang, B., Song, J., Zhao, X., Huang, B., Shi, W., Lu, R., Niu, P., Zhan, F., Ma, X., Wang, D., Xu, W., Wu, G., Gao, G.F., Tan, W. and China Novel Coronavirus Investigating and Research Team. (2020) A Novel Coronavirus from Patients with Pneumonia in China, 2019. N. Engl. J. Med., 382(8): 727-733.

3. Pal, M., Berhanu, G., Desalegn, C. and Kandi, V. (2020) Severe acute respiratory syndrome coronavirus-2 (SARSCoV-2): An update. Cureus, 12(3): e7423.

4. Naji, H. (2020) The emerging of the 2019 novel coronavirus 2019-nCoV. Eur. J. Med. Health Sci., 2(1): 169.

5. Wassenaar, T.M. and Zou, Y. (2020) 2019-nCoV/SARSCoV-2: Rapid classification of betacoronaviruses and identification of traditional Chinese medicine as potential origin of zoonotic coronaviruses. Lett. Appl. Microbiol., 70(5): 342-348.

6. Mousavizadeh, L. and Ghasemi, S. (2020) Genotype and phenotype of COVID-19: Their roles in pathogenesis. J. Microbiol. Immunol. Infect., S1684-1182(20): 30082-7.

7. Wang, H., Li, X., Li, T., Zhang, S., Wang L., Wu, X. and Liu, J. (2020) The genetic sequence, origin, and diagnosis of SARS-CoV-2. Eur. J. Clin. Microbiol. Infect. Dis., 39(9): 1629-1635.

8. Zhang, T., Wu, Q. and Zhang, Z. (2020) Probable pangolin origin of SARS-CoV-2 associated with the COVID-19 outbreak. Curr. Biol., 30(7): 1346-1351.e2.

9. Zhou, P., Yang, X.L., Wang, X.G., Hu, B., Zhang, L., Zhang, W., Si, H.R., Zhu, Y., Li, B., Huang, C.L., Chen, H.D., Chen, J., Luo, Y., Guo, H., Jiang, R.D., Liu, M.Q., Chen, Y., Shen, X.R., Wang, X., Zheng, X.S., Zhao, K., Chen, Q.J., Deng, F., Liu, L.L., Yan, B., Zhan, F.X., Wang, Y.Y., Xiao, G.F. and Shi, Z.L. (2020) A pneumonia outbreak associated with a new coronavirus of probable bat origin. Nature, 579(7798): 270-273.

10. Liu, P., Jiang, J.Z., Hua, Y., Li, L., Zhou, J., Wang X., Hou, F., Chen, J., Zou, J. and Chen, J. (2020) Are pangolins the intermediate host of the 2019 novel coronavirus (2019nCoV). PLoS Pathog., 16(5): e1008421.

11. Hozhabri, H., Piceci, S.F. and Sohrabi, H. (2020) The global emergency of novel coronavirus (SARS-CoV-2): An update of the current status and forecasting. Int. J. Environ. Res.
Public Health, 17(16): 5648.

12. Zhao, J., Cui, W. and Tian, B.P. (2020) The potential intermediate hosts for SARS-CoV-Front. Microbiol., 11(580137): https://doi.org/10.3389/fmicb.2020.580137

13. Yuan, S., Jiang, S.C. and Li, Z.L. (2020) Analysis of possible intermediate hosts of the new coronavirus SARSCoV-2. Front. Vet. Sci., 7 (379): https://doi.org/10.3389/ fvets.2020.00379.

14. Aguirre, A.A., Catherina, R., Frye, H. and Shelley, L. (2020) Illicit wildlife trade, wet markets, and COVID-19: Preventing future pandemics. World Med. Health Policy, 10.1002/wmh3.348. doi:10.1002/wmh3.348.

15. Van-Doremalen, N., Bushmaker, T., Morris, D.H., Holbrook, M.G., Gamble, A., Williamson, B.N., Tamin, A., Harcourt, J.L., Thornburg, N.J., Gerber, S.I., LloydSmith, J.O., de Wit, E. and Munster, V.J. (2020) Aerosol and surface stability of SARS-CoV-2 as compared with SARSCoV-1. N. Engl. J. Med., 382(16): 1564-1567.

16. Meo, S.A., Klonoff, D.C. and Akram, J. (2020) Efficacy of chloroquine and hydroxychloroquine in the treatment of COVID-19. Eur. Rev. Med. Pharmacol. Sci., 24(8): 4539-4547.

17. Karalis, V., Ismailos, G. and Karatza, E. (2020) Chloroquine dosage regimens in patients with COVID-19: Safety risks and optimization using simulations. Saf. Sci., 129(104842): https://doi.org/10.1016/j.ssci.2020.104842

18. Beigel, J.H., Tomashek, K.M., Dodd, L.E., Mehta, A.K., Zingman, B.S., Kalil, A.C., Hohmann, E., Chu, H.Y., Luetkemeyer, A., Kline, S., de Castilla, D.L., Finberg, R.W., Dierberg, K., Tapson, V., Hsieh, L., Patterson, T.F., Paredes, R., Sweeney, D.A., Short, W.R., Touloumi, G., Lye, D.C., Ohmagari, N., Oh, M.D., Ruiz-Palacios, G.M., Benfield, T., Fätkenheuer, G., Kortepeter, M.G., Atmar, R.L., Creech, C.B., Lundgren, J., Babiker, A.G., Pett, S., Neaton, J.D., Burgess, T.H., Bonnett, T., Green, M., Makowski, M., Osinusi, A., Nayak, S., Lane, H.C. and ACTT-1 Study Group Members. (2020) Remdesivir for the treatment of Covid-19 final report. N. Engl. J. Med., 383(19): 1813-1826.

19. Fan, Q., Zhang, B., Ma, J. and Zhang, S. (2020) Safety profile of the antiviral drug remdesivir: An update. Biomed. Pharmacother., 130, 110532. https://doi.org/10.1016/j. biopha.2020.110532

20. World Health Organization. (2020) Situation Report on Coronavirus Disease 2019 (COVID-2019). World Health Organization, Geneva. Available from: https://www.who. int/emergencies/diseases/novel-coronavirus-2019/situation-reports. Retrieved on 26-10-2020.

21. Chan, K.H., Sridhar, S., Zhang, R.R., Chu, H., Fung, A.Y., Chan, G., Chan, J.F., To, K.K., Hung, I.F., Cheng, V.C. and Yuen, K.Y. (2020) Factors affecting stability and infectivity of SARS-CoV-2. J. Hosp. Infect., 106(2): 226-231.

22. ECDC. (2020) COVID-19 Situation Update Worldwide, as of November 9, 2020. Available from: https://www.ecdc. europa.eu/en/geographical-distribution-2019-ncov-cases. Retrieved on 08-11-2020.

23. Centers for Disease Control and Prevention. (2020) Provisional Death Counts for Coronavirus Disease 2019 (COVID-19): Weekly Updates by Select Demographic and Geographic Characteristics. Centers for Disease Control and Prevention, Atlanta, Georgia, United States. Available from: https://www.cdc.gov/nchs/nvss/vsrr/covid_weekly/ index.htm. Retrieved on 09-11-2020.

24. Rizo-Téllez, S.A., Méndez-García, L.A., FloresRebollo, C., Alba-Flores, F., Alcántara-Suárez, R., Manjarrez-Reyna, A.N., Baltazar-López, N., HernándezGuzmán, V.A., León-Pedroza, J.I., Zapata-Arenas, R., González-Chávez, A., Hernández-Ruíz, J., CarrilloRuíz, J.D., Serrano-Loyola, R., Guerrero-Avendaño, G.M. and Escobedo, G. (2020) The neutrophil-to-monocyte ratio and lymphocyte-to-neutrophil ratio at admission predict in-hospital mortality in Mexican patients with severe 
SARS-CoV-2 infection (Covid-19). Microorganisms, 8(10): 1560.

25. Bwire, G.M. (2020) Coronavirus: Why men are more vulnerable to Covid-19 than women? SN Compr. Clin. Med., 4(1-3): doi: 10.1007/s42399-020-00341-w

26. Nikolich-Zugich, J., Knox, K.S., Rios, C.T., Natt, B., Bhattacharya, D. and Fain, M.J. (2020) SARS-CoV-2 and COVID-19 in older adults: What we may expect regarding pathogenesis, immune responses, and outcomes. Geroscience, 42(2): 505-514.

27. Shah, V.K., Firmalm, P., Alam, A., Ganguly, D. and Chattopadhyay, S. (2020) Overview of immune response during SARS-CoV-2 infection: Lessons from the past. Front. Immunol., 11(1949): https://doi.org/10.3389/ fimmu.2020.01949

28. Channappanavar, R., Fett, C., Mack, M., Ten Eyck, P.P., Meyerholz, D.K. and Perlman, S. (2017) Sex-based differences in susceptibility to severe acute respiratory syndrome coronavirus infection. J. Immunol., 198(10): 4046-4053.

29. Omori, R., Matsuyama, R. and Nakata, Y. (2020) The age distribution of mortality from novel coronavirus disease (COVID-19) suggests no large difference of susceptibility by age. Sci. Rep., 10(1): 16642.

30. Atkins, J.L., Masoli, J.A.H. and Delgado, J. (2020) Preexisting comorbidities predicting COVID-19 and mortality in the UK biobank community cohort. J. Gerontol., 75(11): 2224-2230.

31. Nikolich-Zugich, J. (2018) The twilight of immunity: Emerging concepts in aging of the immune system. Nat. Immunol., 19(1): 10-19.

32. Jayaweera, M., Perera, H., Gunawardana, B. and Manatunge, J. (2020) Transmission of COVID-19 virus by droplets and aerosols: A critical review on the unresolved dichotomy. Environ. Res., 188(109819): https://doi. org/10.1016/j.envres.2020.109819

33. Bonato, G., Dioscoridi, L. and Mutignani, M. (2020) Fecaloral transmission of SARS-COV-2: Practical implications. Gastroenterology, 159(4): 1621-1622.

34. Sanche, S., Lin, Y.T., Xu, C., Romero-Severson, E., Hengartner, E. and Ke, R. (2020) High contagiousness and rapid spread of severe acute respiratory syndrome coronavirus 2. Emerg. Infect. Dis., 26(7): 1470-1477.

35. Li, D., Jin, M., Bao, P., Zhao, W. and Zhang, S. (2019) Clinical characteristics and results of semen tests among men with coronavirus disease 2019. JAMA Netw. Open, 3(5): e208292.

36. Zhu, C., Liu, W., Su, H., Li, S., Shereen, M.A., Lv, Z., Niu, Z., Li, D., Liu, F., Luo, Z. and Xia, Y. (2020) Breastfeeding risk from detectable severe acute respiratory syndrome coronavirus 2 in breast milk. J. Infect., 81(3): 452-482.

37. Abdel-Moneim, A.S. and Abdelwhab, E.M. (2020) Evidence for SARS-CoV-2 infection of animal hosts. Pathogens, 9(7): 529.

38. Kiros, M., Andualem, H., Kiros, T., Hailemichael, W., Getu, S., Geteneh, A., Alemu, D. and Abegaz, W.E. (2020) COVID-19 pandemic: Current knowledge about the role of pets and other animals in disease transmission. Virol. J., 17(143): https://doi.org/10.1186/s12985-020-01416-9

39. Olival, K.J., Cryan, P.M., Amman, B.R., Baric, R.S., Blehert, D.S., Brook, C.E., Calisher, C.H., Castle, K.T., Coleman, J.T.H., Daszak, P., Epstein, J.H., Field, H., Frick, W.F., Gilbert, A.T., Hayman, D.T.S., Ip, H.S., Karesh, W.B., Johnson, C.K., Kading, R.C., Kingston, T., Lorch, J.M., Mendenhall, I.H., Peel, A.J., Phelps, K.L., Plowright, R.K., Reeder, D.A., Reichard, J.D., Sleeman, J.M., Streicker, D.G., Towner, J.S. and Wang, L.F. (2020) Possibility for reverse zoonotic transmission of SARS-CoV-2 to free-ranging wildlife: A case study of bats. PLoS Pathog., 16(9): e1008758.
40. Reina, J. (2020) The SARS-CoV-2, a new pandemic zoonosis that threatens the world. Vacunas, 21(1): 17-22.

41. Worldometer. (2020) Nigerian Population. Available from: https://www.worldometers.info/world-population/nigeria-population. Retrieved on 05-11-2020.

42. NCDC. (2020) COVID-19 in Nigeria. Available from: https://www.covid19.ncdc.gov.ng/\#! Retrieved on 03-11-2020.

43. UNFPA. The Power of 1.8 Billion: Adolescents, Youth and the Transformation of the Future Sub-Saharan Africa. Available from: https://www.unfpa.org/sites/default/files/ pub-pdf/ENSWOP14-Report_FINAL-web.pdf. Retrieved on 16-09-2020.

44. Muneer, A., Kumari, K., Tripathi, M., Srivastava, R., Mohmmed, A. and Rathore, S. (2020) Comparative Analyses Revealed Reduced Spread of COVID-19 in Malaria Endemic Countries, MedRXiv.

45. Singh, R. and Vijayan, V. (2020) Chloroquine: A potential drug in the COVID-19 scenario. Trans. Indian Natl. Acad. Eng., 7(1-12): https://doi.org/10.1007/s41403-020-00114-w

46. Chinazzi, M., Davis, J.T., Ajelli, M., Gioannini, C., Litvinova, M., Merler, S., Piontti, A.P.Y., Mu, K., Rossi, L., Sun, K., Viboud, C., Xiong, X., Yu, H., Halloran, M.E., Longini I.M. Jr. and Vespignani, A. (2020) The effect of travel restrictions on the spread of the 2019 novel coronavirus (COVID-19) outbreak. Science, 368(6489): 395-400.

47. Vanguard Newspaper. Nigerians Only Use Face Mask to Evade Police Harassment. Available from: https://www.vanguardngr.com/2020/05/nigerians-only-use-face-masks-toavoid-police-harassment-erigga. Retrieved on 30-10-2020.

48. Jaja, I.F., Anyanwu, M.U. and Jaja, C.J.I. (2020) Social distancing: How religion, culture and burial ceremony undermine the effort to curb COVID-19 in South Africa. Emerg. Microb. Infect., 9(1): 1077-1079.

49. Taha, S.A.H., Osman, M.E.M. and Abdoelkarim, E.A.A. (2020) Individuals with a Rh-positive but not Rh-negative blood group are more vulnerable to SARS-CoV-2 infection: Demographics and trend study on COVID-19 cases in Sudan. New Microbes New Infect., 38(100763): doi: 10.1016/j.nmni.2020.100763.

50. Kruse, H., Kirkemo, A.M. and Handeland, K. (2004) Wildlife as source of zoonotic infections. Emerg. Infect. Dis., 10(12): 2067-2072.

51. Vora, N.M., Osinubi, M., Wallace, R.M., Aman-Oloniyo, A., Gbadegesin, Y.H., Sebastian, Y.K., Saliman, O.A., Niezgoda, M., Davis, L., Recuenco, S. and Centers for Disease Control and Prevention. (2014) Assessment of potential zoonotic disease exposure and illness related to an annual bat festival-Idanre, Nigeria. MMWR Morb. Mortal. Wkly. Rep., 63(15): 334.

52. Islam, M.R., Hoque, M.N., Rahman, M.S., et al. (2020) Genome-wide analysis of SARS-CoV-2 virus strains circulating worldwide implicates heterogeneity. Sci. Rep., 10(14004): https://doi.org/10.1038/s41598-020-70812-6.

53. World Health Organization. (2020) SARS-CoV-2 Variant United Kingdom of Great Britain and Northern Ireland. World Health Organization, Geneva. Available from: https://www.who.int/csr/don/21-december-2020-sars-cov2variant-united-kingdom/en. Retrieved on 31-12-2020.

54. Terry, M. (2020) Mutated COVID-19 Viral Strain in U.S. and Europe 10 Times More Contagious than Original Strain. Available from: https://www.biospace.com/article/mutatedcovid-19-viral-strain-in-us-and-europe-much-more-contagious. Retrieved on 12-11-2020.

55. Wang, J., Tang, K., Feng, K., Lin, X., Lv, W., Chen, K. and Wang, F. (2020) High Temperature and High Humidity Reduce the Transmission of COVID-19. Cornell University, New York. 